\title{
Alacranes en La Habana: el CUento policial CUbano de Lino Novás Calvo*
}

SCORPIONS IN HAVANA:

LINO NovÁs CaLVO'S CUBAN DETECTIVE FICTION

Jesús Gómez-de-Tejada

Universidad Autónoma de Chile

Santiago do Chile, Chile

\section{Resumen}

Este artículo enfoca los ocho cuentos policiales que Lino Novás Calvo publicó en la revista Bohemia entre 1948 y 1952 . Se presentan estos textos como antecedentes del neopolicial cubano contemporáneo, especialmente caracterizado por el profundo signo social de sus narraciones. El contraste entre diversos escritos del autor (cartas, artículos y los propios cuentos policiales) permite establecer la importancia que este concedió a la atmósfera y a los personajes que pueblan sus relatos, en cuya representación se concilia lo cubano y lo universal. Ambientes deletéreos y seres alacranados le posibilitaron profundizar en el lado más desgarrado de una sociedad habanera caracterizada, según él, por la falsedad, la violencia y la corrupción. Finalmente, se subraya cómo la inmediatez de espacios y acontecimientos, el reflejo de circunstancias político-sociales -el bonchismo, especialmente- y el registro de modalidades lingüísticas propias del contexto son usados por Novás Calvo como recursos para representar La Habana con total nitidez.

Palabras claves: Lino Novás Calvo, 8 narraciones policiales, cuento cubano, neopolicial cubano, narrativa policial latinoamericana, Bohemia.

\section{Resumo}

O presente artigo está focado nos oito contos policiais que Lino Novás Calvo publicara na revista Bohemia entre 1948 e 1952. Apresenta-se esses textos como antecedente do neopolicial cubano contemporâneo, que está especialmente caraterizado pelo profundo signo social das suas narrativas. A confrontação entre diversas produçóes do autor (cartas, artigos e contos policiais) permite estabelecer a importância que Novás Calvo deu à atmosfera e às personagens que habitam seus relatos, conseguindo harmonizar o cubano com o universal. Ambientes deletérios e seres depravados permitiram-

\begin{abstract}
This article focuses on the eight detective stories published by Lino Novás Calvo in the magazine Bohemia between 1948 and 1952. These texts are presented as precedents of the contemporary Cuban detective fiction (neo-policial), characterized by the deep social nature of its narrations. The contrast displayed in various writings by this author letters, articles, and the aforementioned detective stories-, reveals the importance bestowed upon both the atmosphere and the characters in those fictions, where the Cuban and the universal essences coexist. Tainted places and scorpion-like
\end{abstract}


lhe se aprofundar nos espaços mais perversos de uma sociedade havanesa caraterizada, segundo o escritor, pela falsidade, a violência e a corrupçáo. Finalmente, destaca-se como é usado por Novás Calvo a convergência de espaços e acontecimentos, a incidência de circunstancias político-sociais -especialmente o bonchismo- e o registro de modalidades linguísticas próprias do contexto; como recurso para mostrar uma Havana com total nitidez.

Palavras-chave: Lino Novás Calvo, 8 narraciones policiales, conto cubano, neopolicial cubano, narrativa policial latino-americana, Bohemia. creatures make possible for Novás Calvo to dive into the forsaken side of a society in Havana characterized, in his vision, by falsehood, violence, and corruption. Finally, the article highlights how the immediacy of events and contexts, the reflection of the socio-political scene -the bonchismo, particularly- and the register of the different linguistic modalities, are all used by the author as resources to depict Havana unambiguously.

Keywords: Lino Novás Calvo, 8 narraciones policiales, Cuban Short Stories, Contemporary Cuban Detective Fiction (neo-policial), Latin American Detective Narrative, Bohemia.

Gente que te encuentras en el cinturón que empieza en la

Chorrera y termina en Casablanca, pasando por Puentes Grandes [...] gente alacranada que formará y está formando la materia prima de muchos de mis cuentos ${ }^{1}$. (NOVÁS CALVO, 2008a, p. 135)

Gran parte de la narrativa breve criminal de Lino Novás Calvo se presenta como crónica periodística de sucesos proclamados como reales, ${ }^{2}$ que un periodista anónimo o incorporado a la ficción con el nombre del propio autor-Novás Calvo- da a la luz pública como resultado de la "saludable labor de hurgar en los lodos profundos de ciertos sucesos de sangre ensombrecidos y revueltos" (NOVÁS CALVO, 1995, p. 31)3. Esta afirmación, contenida en la confesión epistolar que el asesino de "La yegua ruina y el tiro chiquito" dirige a un Novás Calvo intradiegético, supone una declaración explícita de la adhesión del escritor a la vertiente realista del género, aquella donde el delito "is frequently seen as endemic within social institutions, rather than

\footnotetext{
*Este trabajo se enmarca en el Proyecto FONDECYT Iniciación 2017 no 11171169 (CONICYT, Chile), que lleva por título "Calibre corto: sendas del cuento policial cubano", del que soy investigador responsable. 1 Mi énfasis.

2 Para otras informaciones sobre esta relación entre el relato policial y la crónica roja en la obra de Novás Calvo puede verse Gómez-de-Tejada (2013b).

3 Lino Novás Calvo. 8 narraciones policiales. Santiago de Cuba: Oriente, 1995. Todas las citas corresponden a esta edición. A partir de aquí, se indicará solo el número de página entre paréntesis.
} 
as an individual transgression" y que "reveals a chaotic and violent society of 'failure' which yearns for a 'lost utopia'” (OAKLEY, 2011, p. 2).

En estos relatos, publicados por Novás Calvo en la revista habanera Bohemia entre 1948 y 1952 -compilados por José M. Fernández Pequeño en 1995 bajo el título 8 narraciones policiales-, ${ }^{4}$ es obvia la elección del hardboiled estadounidense y su autoproclamada afinidad con la narrativa de James M. Cain, Dashiell Hammett o Raymond Chandler ${ }^{5}$. Los personajes de estos cuentos son amasados con la arcilla cenagosa de los suburbios de las grandes urbes, donde la incógnita arrojada por el crimen se resuelve o persiste en medio de la penetración en los demonios interiores de estos seres - "sacados de los rincones envenenados de la tierra" (NOVÁS CALVO, 1995, p. 101)-y en la revelación de la corrupción de la sociedad que los determina y acorrala. Esta línea, mantenida desde su aparición como poeta social en las páginas de la Revista de Avance y en la publicación de sus principales colecciones de relatos ${ }^{6}$, lo convierte en un precursor de la práctica contemporánea del policial hispanoamericano:

Unlike traditional detective fiction in English, the majority of detective fiction in Spanish is comprometido, or social committed. For [...] Cuban authors, the very marginality of detective literature has allowed it to evolve into a tool of social criticism in a climate where the official press is unwilling or unable to perform this function. (BRAHAM, 2004)

4 Los títulos de los relatos y las fechas de publicación en Bohemia son "El santo del cerillo" (10 de octubre de 1948), "Un sábado por la tarde" (18 de diciembre de 1949), “ ¡Y baila y baila y baila!" (22 de abril de 1951), "La yegua ruina y el tiro chiquito" (17 de junio de 1951), "Un paseo por la Quinta Avenida" (29 de julio de 1951), "Historia de un asalto" (26 de agosto de 1951), "El asesinato televisado" (1 de julio 1952; al final de este se ofrece la fecha y el lugar de composición: "La Habana, marzo de 1952"), "Elsa Colina y los tantos millones" (31 agosto de 1952).

5 Además de estos ocho relatos, según el propio Novás Calvo, escribió dos novelas cortas policiacas para Bohemia, de las que no da título alguno y que al parecer no vieron la luz. En su epistolario también menciona las dos novelas cortas, "Billete entero" y "Yo y Mrs. Díaz"-sin que quede claro si estas son o no las mismas mencionadas anteriormente. Novás Calvo afirma que intentó publicarlas sin fortuna en la editorial Espasa y en la revista Cuadernos Hispanoamericanos. De las primeras dice que son "tentativas de novelitas policiacas [...] sin estilo [...] tenían, sin embargo, asuntos originales, y temas cubanos por medio"; las dos últimas las define como "crime stories bastante extrañas" (NOVÁS CALVO, 2008a, p. 116, 137). Hasta donde sé, el último de sus relatos criminales es "Crónica roja” publicado en la revista Exilio en 1973.

6 En 1928 su irrupción en la vida cultural habanera se produjo a través de un poema de corte social enviado a la revista dirigida entre otros por Jorge Mańach y Francisco Ichaso. Por aquel entonces, Novás Calvo ejercía uno de los oficios que más le marcaron y que reflejó abundantemente en su literatura: el de fotinguero (taxista). En vida, publicó tres colecciones de cuentos: La luna nona y otros relatos (1942), Cayo Canas (1946) y Maneras de contar (1970). 
Para Braham "the Latin American detective genre is also flourishing, on its own merits and as a source for other literary experimentation" (BRAHAM, 2004, p. ix). Así ocurre en los relatos policiales de Novás Calvo, que a través de ellos trata de encontrar una senda para la narración no genérica y que los contempla como la solución para el anquilosamiento intelectualista de la novela durante el por entonces aún reciente pasado vanguardista de esta modalidad (NOVÁS CALVO, 2008d, p. 428)7. Esta perspectiva es expuesta en el artículo "Un error de Alfonso Reyes" publicado en junio de 1945, en la columna que asiduamente escribía para el periódico Información.

Además de ser una vía para el ensayo de nuevas formas de narrar, el policial se ofreció a Novás Calvo, desde el comienzo, como un cauce para la proyección literaria de asuntos y ambientes cubanos". En el ensayo "Novela por hacer" (aparecido en Revista Bimestre Cubana en junio de 1941), el escritor se refiere al escaso aprovechamiento que habían sufrido numerosos espacios y tipos de la isla: los cayos, las ciudades de provincia, el barrio chino, el mar e incluso el propio ingenio azucarero. La novela cubana, argumenta, debe ser "el reflejo directo y animado de este mundo que nos rodea y que bueno o malo nos ha dado su savia" (NOVÁS CALVO, 2008b, p. 405). Por ello, expresa que la atmósfera es el más determinante elemento a tener en cuenta en la singularización de la producción cubana:

Un hotel pobre de París no es igual a un hotel de la misma categoría en La Habana: los personajes del primero no pueden ser los del segundo; aun cuando buscáramos, intencionalmente, unos tipos exteriormente similares, su comportamiento tendría que ser bien distinto: un mismo argumento, si los personajes, en uno y otro caso, se portan conforme a sí mismos, daría una obra de arte completamente distinta. Esto, aparte de que los móviles, y los elementos externos que lo modifican, no pueden ser los mismos allí que aquí. (NOVÁS CALVO, 2008b, p. 400)

7 El carácter innovador de Novás Calvo puede comprobarse en la mayor parte de los géneros y obras que cultivó. Espinosa Domínguez subraya este aspecto de su narrativa desde el propio título de su tesis: Entre la provincia y el mundo: modernidad e innovación en la narrativa de Lino Novás Calvo Calvo. Entre los autores que resaltaron el carácter pionero de su expresión se encuentran José Antonio Portuondo, Enrique Anderson-Imbert y Alberto Gutiérrez de la Solana.

8 La preocupación por experimentar y encontrar técnicas narrativas originales se apunta explícitamente en el título de la tercera y última colección de cuentos publicada ya el exilio de Nueva York tras la revolución castrista: Maneras de contar. En una entrevista afirmó que "Me ha tocado surgir en una encrucijada literaria, y en todo el tiempo que llevo escribiendo no he hecho más que tantear, en procuración de un estilo que se ajustara a lo que yo quería expresar" (BATISTA, 1972, p. 22). 
En la epístola a la que pertenece el paratexto inicial, dirigida a José Antonio Portuondo en julio de 1948, Novás Calvo se refiere a la condición social y humana de los protagonistas habaneros de los relatos que por entonces ansiosamente se esforzaba en componer'. En su carta Novás Calvo diferencia la gente humilde conocida en La Habana en las primeras décadas del siglo XX, o en París y en Madrid durante los años treinta, de aquella otra observada a fines de los cuarenta en ciertos suburbios habaneros. Frente a la "humildad cristiana" de los primeros, destaca el envilecimiento de los segundos, que se estaban "acanallando", hundidos en un proceso de corrupción, en el que parece incluir al resto de la sociedad cubana y a sí mismo (NOVÁS CALVO, 2008a, p. 135).

El hombre o la mujer alacranados, define el DRAE, son aquellos "inficionad[os] de algún vicio, peste o enfermedad". Los protagonistas de las 8 narraciones policiales, los alacranes o aquellos pervertidos por el escozor de su picadura, aunque rechazados desde un plano cívico, son el barro principal de la humanidad de estos textos, productos y reflejos de La Habana corrompida recreada y vivida por el autor, que en 1951 aún se lamentaba de "ver cuánto material bueno está pasando y nadie lo aprovecha. Por bueno, quiero decir, desde luego, malo, pues parece que lo malo es el elemento nutricio del arte" (NOVÁS CALVO, 2008a p. 152). Precisamente, es la maldad la que atrae la atención creativa de Novás Calvo de forma persistente y uno de los rasgos que en Hammett le resultan más embriagadores. Del autor de Red Harvest (1929) destacó la creación de personajes inmediatos caracterizados por un lenguaje y unas motivaciones populares, salpicados de cierto romanticismo antiheroico: "personas de carne y hueso, con su tono, su argot y su dejo de pueblo. [...] gentes malas, que son los que hacen la historia" (NOVÁS CALVO, 2008c, p. 412) ${ }^{10}$.

Por otra parte, el comentario metatextual de uno de los protagonistas de los relatos califica el conjunto humano incluido en la serie como "colección de criminales incomprendidos" (31). Estos protagonistas son víctimas de diversas situaciones de violencia, chantaje, opresión o complot urdidos por criminales de diversa categoría. Desde esta perspectiva, puede dividirse en dos los grupos de personajes que transitan por los laberintos delincuenciales de su Habana y alrededores: alacranes y alacranados, victimarios y víctimas, poderosos y aquellos emponzońados por el veneno del poder, estos últimos nunca completamente inocentes. Así lo proclama para sí misma y con febril

9 Cira Romero ha recopilado las cartas que Novás Calvo envió a Portuondo entre 1944 y 1952 en Laberinto de fuego. Epistolario de Lino Novás Calvo (2008).

10 Mi énfasis. Un estudio de la importancia de los artículos "Un error de Alfonso Reyes" y "Hammett y Cain" en el desarrollo del proyecto policial de Novás Calvo puede verse en Espinosa Domínguez (2004, p. 231-237) y Gómez-de-Tejada (2013a, p. 607-610). 
nitidez Dulce Rosario Timiraos, una de las protagonistas de "广Y baila y baila y baila”, cuento que llegó a ser comprado para su adaptación cinematográfica por el estudio Productora Fílmica: “¡Estoy enferma! ¡Estoy envenenada! A veces siento el impulso de gritar: ‘AApártense, que tengo rabia!' Pero no a él. Él es quien me ha mordido. ¡Ahora él va a ser el mordido!” (103).

\section{La Habana en alta fidelidad}

El hard-boiled trajo frente a su predecesora, la novela enigma, un cambio fundamental en la creación del escenario que albergaba el devenir de personajes envueltos en un asunto criminal. Frente a los formularios espacios cerrados que solían acompañar las a menudo sedentarias elucubraciones de los pulcros detectives de la versión inglesa, apareció un ámbito esencialmente abierto que posibilitó el deambular de otro tipo de investigador por las calles de una ciudad construida ante el lector como un espacio viciado y absorbente. A través de este ámbito, la novela policial abría una ventana hacia la sociedad: "se preferirá retratar lugares públicos, calles, barrios, la ciudad, pues el detective necesita moverse libremente por estos espacios para dar constancia de las desigualdades sociales, del crimen, de la delincuencia [...] para que uno de sus pilares básicos, como es la crítica social, pueda tratarse" (MARTÍN CEREZO, 2006, p. 80-81).

La Habana de Novás Calvo no aparece dibujada con la minuciosidad descriptiva de la ciudad característica del neopolicial hispanoamericano iniciado hacia los ańos noventa por autores como el cubano Padura o el mexicano Paco Ignacio Taibo II: uno de esos "richly detailed urban settings become protagonists in their own right" (BRAHAM, 2004, p. XV). Su narrativa esencialmente elíptica, llena de sobreentendidos que ponen en juego la complicidad del lector, alcanza también el escenario, que se esboza a través de detalles y trazos que surgen imbricados a la acción y al habla de los sujetos de la ficción. El detective de Padura, Mario Conde, recorre las calles de La Habana del Periodo Especial reflejando "a society on the brink of economic and moral collapse" (BRAHAM, 2004, p. XV). Por su parte, los protagonistas de Novás Calvo serpentean a través de los rincones de esta ciudad acosados por la arbitrariedad de un oscuro poder y una ausencia de ética surgidos al amparo de la corrupción generalizada de la Cuba de fines de los años cuarenta y principio de los cincuenta. Sus peripecias transcurren en medio de la violencia cotidiana de los bonches o cuadros paramilitares y seudopoliciales que se enfrentaron por prebendas políticas durante los gobiernos que siguieron a la caída de Gerardo Machado en 1933. Así parece ponerlo de manifiesto Wilkinson cuando señala que, en todas sus historias criminales para Bohemia, Novás Calvo crea un mundo sin fe en la justicia, 
una realidad urbana "very similar to the world of Dashiell Hammett's fiction" (WILKINSON, 2006, p. 106).

La preocupación social y el gusto por el ambiente cubano de Novás Calvo, que no renuncia a la universalidad de los destinos y ansiedades de sus personajes, convierte La Habana en un fondo discreto, pero omnipresente. Tal y como afirma Geherin en su estudio Scene of the Crime, "when a writer uses location as more than backdrop by weaving it into the very fabric of the novel, affecting every other element of the work, the reader gets far more than local color" (GEHERIN, 2008, p. 3). Novás Calvo escoge el escenario con claridad: calles, ambientes, lenguaje y tipos son ampliamente habaneros y marcan la escritura desde el comienzo de su acercamiento a la narrativa policial. Esta afirmación es explicitada en una de las cartas a Portuondo: "también yo pensé en el género, porque tiene salida y daría oportunidad de explotar ambientes cubanos muy buenos” (NOVÁS CALVO 2008a, p. 113).

La Habana criminal de Novás Calvo -al igual que aquella de sus cuentos no genéricos, los primeros según Guillermo Cabrera Infante donde se escuchó la capital cubana "por vez primera en alta fidelidad" (CABRERA, 1998, p. 116) - se construye a través del lenguaje del narrador y los personajes, de la mención de calles, de la referencia a hechos y lugares de la historia y la realidad isleńa que van jalonando las vicisitudes de unos seres de impulso universal, pero de ademanes, costumbres y aspecto esencialmente cubanos. El propio Portuondo ofreció una crítica temprana sobre esta vertiente de la creación de Novás Calvo donde destaca la veta idiosincrática de los textos aparecidos en Bohemia: "versión cubana de ese tipo de narración detectivesca en algunos cuentos bien logrados [...]. En ellos, lenguaje y ambiente se conciertan para lograr la total aclimatación de procedimientos puestos en voga por Hammett, Chandler, Cain y, últimamente, Cornell Woolrich" (PORTUONDO, 1973, p. 109).

La íntima conexión de estos relatos con la crónica de sucesos se subraya en una reconocible función de crítica social, conectada tanto a aspectos recurrentes de la literatura novascalviana como a rasgos determinantes de la narrativa policial realista. Sin dogmatismo y plenamente integrados en el discurso, estos elementos sociales se ofrecen como reflejo de la realidad habanera del momento, como demuestra el reiterado empeño por despertar en el lector el recuerdo de los hechos, recurso que a la vez potencia la verosimilitud de lo narrado y acrecienta su cercanía temporal. Fernández Pequeño llama la atención sobre el extremo que supone en este propósito "Un paseo por la Quinta Avenida" publicado apenas unos días después de la conclusión del tiempo fabular (26). Por su parte, Espinosa Domínguez señala la excepcionalidad de "El asesinato televisado" localizado en un futuro inmediato: a "fines de la quinta década" (56). Más allá de estos ejemplos máximos, el autor utiliza 
cierta variedad de recursos con este fin. Estos son la constante apelación a la reciente memoria colectiva, la especificación de la fecha exacta, el empleo de alusiones más imprecisas (sobre la década, mes o acontecimientos notorios en la reciente historia cubana relacionados con el crimen o con la climatología), o el uso de comentarios enfáticos sobre la necesidad de silenciar los nombres de los implicados o sustituirlos por otros: "Voy a recordarlo. Pero antes, ése no es su nombre. Ni ése, ni los otros. Demasiado cerca; demasiado viva aún esta historia" $(173)^{11}$.

La proximidad en el tiempo se refuerza con la inmediatez espacial conseguida a partir de la designación de múltiples escenarios urbanos y naturales según el callejero y la toponimia cubana. Se menciona la ciudad de La Habana y sus calles Virtudes, Galiano o la Quinta Avenida, el río Almendares, la zona de la Chorrera o de los muelles, la población el Ateje, o referencias difícilmente identificables por un lector no habanero: "aquí, en el edificio Guereña" (145), "en la esquina, frente a la Imperial Austriaca" (204). Curiosamente, en un fragmento de su epistolario Novás Calvo confirma el protagonismo que en "Historia de un asalto" concede al Almendares y parece anticipar el desenlace irónico donde la crecida del río arrebata a la protagonista el dinero obtenido tras el asesinato de su amante: "Por aquí, a la caja. Todo el mundo apuchinchándose. Hasta el pobrecito Almendares lleva billetaje en vez de agua sucia” (NOVÁS CALVO, 2008a, p. 150).

Otros recursos más genéricos vienen determinados por la descripción de un tipo contemporáneo de vida como se percibe en los hábitos del doctor Riquelme y de Monona Mayegüe, o en el uso de la trusa de plata de Elsa Colina y la novedad de las cabinas en la playa. E incluso, la aparición de la televisión, que en Cuba tiene lugar precisamente en los años cincuenta ${ }^{12}$; así como la alusión al "Carlos Manuel" en "Un sábado por la tarde", puesto que se trata de un billete de 10 pesos que se imprimió por primera vez en 1939 y que en 1949 conoció una nueva emisión con diversas modificaciones. Otro posible canal para la concreción de un tiempo de acción cercano a la escritura

11 En "El asesinato televisado" primero se dice que "todo el mundo sabe que fue el crimen más resonante de la quinta década" (56), y más adelante se añade que ciertos sospechosos "estuvieron fuera el 17 y 19 de agosto" (72). En "Historia de un asalto" se lee: "todo el mundo recuerda aquellas lluvias. Duraron del 23 al 27 de junio sin cesar" (97). En "La yegua ruina y el tiro chiquito" se señala que "la acción empezó el jueves siete de junio" (47), pero no se precisa el año. Las concreciones mayores se presentan en "Un paseo por la Quinta Avenida": "es lo que estaba ocurriendo aquella mańana, 17 de julio de 1951, en La Habana” (200); y en “¡Y baila y baila y baila!”: “a mediados de marzo de 1951” (101).

12 Thomas comenta la implantación de este avance tecnológico en Cuba en relación con el caos político y el despilfarro económico del momento: "Por toda Cuba se extendió un sentimiento de desesperanza, que en modo alguno fue aliviado por la continua prosperidad y por las novedades tecnológicas que resultaban de gran importancia para Cuba: el 24 de octubre de 1950 la televisión, inaugurada por Prío, empezó sus emisiones; como corría el dinero, todo el mundo se apresuró a comprar televisores” (THOMAS, 1974, p. 994). 
es la introducción de ciertos anglicismos referidos a la moda (slacks), la bebida ( highball), la casa (loge), etc.

El lector de la época podía reconocer esa inmediatez justamente en la pintura de la sociedad en la que él mismo se desenvolvía y que a grandes rasgos se caracterizaba por el "pandillerismo, el caciquismo, la corrupción, la manipulación del poder" (FERNÁNDEZ PEQUEÑO, 1995, p. 27): "En la tribuna, con Porta Poisse, estaba su plana mayor. Casi todos sus amigos eran letrados. Lo eran especialmente los doctores Gredín, Cadáver, Maró, Salcón, Ceraste: Todos, figuras ilustres en su tiempo. Detrás de ellos, por orden gradual, disminuyendo de importancia y relieve, estaban los otros cuadros, los cuadros de acción y tiro" (p. 57). La ironía contenida en el término letrado, sinónimo de doctor, debía ser inmediata para el receptor cubano y hacía alusión a la vinculación mortífera y espuria entre el gansterismo y la universidad de la que procedían estos supuestos egresados, cuya fama se debía exclusivamente al uso partidista de la fuerza.

Aguiar Rodríguez en su estudio El bonchismo y el gangsterismo en Cuba (2000; citado por Romero en NOVÁS CALVO, 2008a, p. 172) hace un minucioso seguimiento de las causas del origen y desarrollo de un tipo de violencia que supuso una de las principales lacras de los periodos constitucionales surgidos a partir de la caída de Gerardo Machado. El bonchismo, incubado durante los "gobiernos marionetas" constituidos a la sombra de Fulgencio Batista, alcanzó un gran desarrollo entre 1940 y 1944, interregno en que Batista fungió como presidente de la República. Finalmente, el pandillerismo mantuvo una intensa actividad dentro de los regímenes auténticos de Ramón Grau San Martín (1944-1948) y Carlos Prío Socarrás (1948-1952). Según Aguiar Rodríguez, estas bandas armadas de gánsteres, que acabaron formando parte integral de la estructura política de la isla, tuvieron su origen en el bonchismo. Este autor afirma que se trató de un "episodio netamente estudiantil" (AGUIAR RODRÍGUEZ, 2000, p. 1), justificado por el arraigo de elementos mafiosos en la dirección de los movimientos asociados al ámbito educativo, primero dentro de los centros de segunda enseñanza y después de los universitarios.

Los miembros de los bonches eran hombres de gatillo alegre, de acción, guapetones -como de forma diversa se les llamó-. Según refleja Novás Calvo en "La yegua ruina y el tiro chiquito" y "El asesinato televisado", las disputas por los favores políticos del gobierno de turno o por rencillas personales hicieron que "los atentados contra los cabecillas de esos grupos o contra figuras políticas [llegaran] a constituir noticia habitual en la prensa" (AGUIAR RODRÍGUEZ, 2000, p. 38-39). Tal circunstancia propició que cinco de estos ocho relatos criminales cuenten con un doctor entre sus personajes secundarios. Este reflejo de un "bonchismo desbocado", según las palabras 
usadas por Novás Calvo en carta a Portuondo en 1947 (NOVÁS CALVO, 2008a, p. 124), sirve de detonante de la acción y permite dibujar como trasfondo la carcomida administración del país. Los doctores Codo, Astero Mirán, Porta Poisse, Millares y el referido como "hermanastro" (el único del conjunto en acabar en la cárcel y que aparece sin nombre propio en "Un paseo por la Quinta Avenida") forman una colección representativa de un tipo social de la época, cuya condición genérica se acentúa en la pintura común de sus trayectorias, actitudes y hábitos.

El carácter letal de los doctores como jefes de pandillas mafiosas armadas se inserta en la sociedad hasta el punto de que justifica en algunos cuentos esporádicas alusiones irónicas a su mortífera actividad. De este modo, en "El santo de cerillo" (en principio, alejado de esta temática), Monona Mayegüe apostrofa con sorna al Dr. Riquelme al decirle que le "estaba haciendo falta un doctor, de los que curan" (p. 149). Mientras en "El asesinato televisado", al dar noticia de la muerte de un médico, el narrador contrapone la figura del facultativo a la de los otros doctores: "Un amigo de ella [Nena Boliva, esposa del Dr. Porta Poisse] -y de los otros doctores-, el doctor (en Medicina) Bover Altona había sido hallado muerto" (p. 64) ${ }^{13}$.

Los métodos sanguinarios de estos líderes hampones se evidencian también en los hechos relatados en "Elsa Colina y los tantos millones", " $\mathrm{Y} Y$ baila y baila y baila!" y "Un paseo por la Quinta Avenida”. En estos tres textos, más allá del destino final que encuentran -muertos o encarcelados, víctimas de la venganza de seres oprimidos bajo su poder (antiguos colaboradores, familiares, examantes)-, se aprecia de modo más o menos indirecto la estructura organizativa de las bandas, se registra con cierta ambigüedad la naturaleza inicua de sus negocios y se enfatiza el vertiginoso enriquecimiento obtenido a partir de ellos. Las conspiraciones y la corrupción generada por la ambición de las distintas fuerzas se filtran también a través del monólogo de Marta Laforet, protagonista de "Un paseo por la Quinta Avenida", que trata de huir de las maquinaciones de uno de esos doctores: "era una trama. Y no sólo traman los asesinos, y los policías, sino también sus víctimas. Yo estaba tramando" (p. 211); o en el circunstancial diálogo de este personaje con una anónima ciudadana, que no duda en achacar al gobierno la responsabilidad de la violencia que acababan de contemplar y para la cual exige un pronto final (p. 214-215).

La improbidad de tales caciques se actualiza en la sombra de los funestos lugartenientes o del personal de confianza que cumplen sus órdenes y los convierten en personalidades de muy difícil acceso. Thomas, que destaca el fatídico rol de las bandas en la violencia y corrupción de los gobiernos de

13 Mi énfasis. 
Grau y Prío, apunta como, a pesar de aprobarse una "ley contra el gangterismo [sic]", todo continuó igual: "Masferrer, que ahora era senador de los auténticos, viajaba por Cuba en su Cadillac como un rey pirata, rodeado de guardaespaldas" (p. 988) ${ }^{14}$. Destaca en ese sentido la mención de "Los Zocotrocos", cuerpo de guardia del temible doctor de "Un paseo por la Quinta Avenida" y, sobre todo, la del sombrío factótum Orestes Valencia, descrito como "un hombre más alto, más delgado, más prieto, de ojos de sapo y dientes mellados" (p. 193).

"La yegua ruina y el tiro chiquito" constituye la crónica literaria del ascenso, auge y caída de El Mayor, sobrenombre del doctor Astero Mirán, que incluye el declive y asesinato de su mentora y amante la doctora Florencia Ferrer Almera o, simplemente, La Doctora ${ }^{15}$. La voz expiatoria del narrador, que se autocalifica como "secretario" u "oficial de enlace" del doctor, realiza un recorrido por la organización de gánsteres dirigida por este último. En su relato, alude a los comienzos del Mayor de mano de La Doctora, la obtención del poder, el enfrentamiento con los "gatilleros" de la banda rival, los alardes de autoridad, los conciliábulos celebrados en diferentes fincas de las afueras de La Habana y las conexiones políticas y policiales que permitían sus actividades:

Esa noche acudió a La Casimba la sección de operaciones. Todo era así: planes, cartografía, operaciones, información... como en un estado mayor, aunque ni él ni los suyos (los buenos) habían sido nunca militares [...] En seguida entraron en consejo con El Mayor en el pent y salieron a las dos horas erguidos y dispuestos. Su jefe (me reservo su nombre) se volvió hacia El Mayor en el umbral y le dijo:

-Bueno Mayor, ya usted sabe. Si no vuelvo, no se olvide de mandarme flores. Volvió... a los tres días. En tanto, los periódicos relataban el pase o pasada que le habían dado a una máquina en que viajaba (sin duda) gente de Jorungo. Tres habían resultado muertos, uno herido; pero el "cuñadito" había resultado milagrosamente ileso. La policía, desde luego, perseguía muy de cerca de los autores. (p. 39)

La violencia pandillera de este relato deja paso a las redes de corrupción observadas en "El asesinato televisado". Aquí las altas esferas de la política son retratadas con ciertos rasgos caricaturescos que desvían la focalización de la narración hacia las doctoras consortes, convertidas en una sórdida galería de

14 Rolando Masferrer fue uno de los pandilleros más conocidos de la época, antiguo comunista y fundador del MSR, había luchado contra Machado, y combatido en la guerra civil española. Reinaldo Arenas se acuerda de él en su autobiografía, Antes que anochezca (1992): "Masferrer era un político cubano y a la vez un gánster; términos que no se excluyen” (ARENAS, 2010, p. 69).

15 Pueden apreciarse concomitancias evidentes entre este personaje y Dulce Rosario Timiraos la "antigua revolucionaria, excompañera y amiga del Dr. Moliner” (101) en “¡Y baila y baila y baila!”, no solo en su caracterización sino también en la relación con el doctor y los deseos de venganza respecto a él. Incluso hay un pasaje similar en el que ambos cuentos relatan las burlas del gánster hacia la compañera del pasado. 
viudas con "peinados crines-al-viento" sospechosas de adulterio y robo. La evasión de divisas, los negocios oscuros y la violencia institucional denunciada como perversión del sistema gubernamental se concretan además en hechos tangenciales como el asesinato del facultativo Bover Altona, cuyo cadáver aparece acompañado de una nota de aviso - "Para que no seas lengualarga" (p. 64)-; o las irregularidades en la obtención de empleos públicos: "ella tenía ya a alguien averiguando. Era un hombre fino, atrevido, resbaloso. Se llamaba Delio Pardo Cabañas, y era teniente. Nena misma lo había hecho teniente" (71). En varias ocasiones se menciona la tenebrosa ascensión al poder y la riqueza amasada por los pandilleros. El ocultamiento del dinero ilícitamente adquirido da origen a toda la trama de "Elsa Colina y los tantos millones" y es parte integral del argumento de "El asesinato televisado".

La conciencia colectiva de los habaneros en cuanto a la existencia de tan siniestras fortunas se hace palpable en un fragmento de carta de diciembre de 1951 del autor a Portuondo. En ella, con punzante cinismo, Novás Calvo comenta la espiral de connivencia entre delito y poder que envuelve la capital, convertida en atmósfera de sus relatos negros: "La Habana es algo fantástico. Casi todo el mundo tiene máquina. Famas y fortunas se hacen en dos días, o en dos horas. Una verdadera locura de sexo y amillonamientos. Sin contar la 45 y otros calibres. Pero esta es la sal de la fiesta. A mí me encanta. Policarpo, lo creo sinceramente, es un tipo formidable" (NOVÁS CALVO, 2008a, p. 152) ${ }^{16}$.

Otro elemento, aunque de menor presencia, con que el autor pretende acercarse a la realidad habanera es la descripción de la protagonista de "Historia de un asalto", cuya cesantía la sume en un estado de melancolía y dócil astenia ante la amoralidad del delito. Dicha situación de desempleo cobra matices arquetípicamente galdosianos en el padre de la joven:

En una casa ya vieja, pero todavía sin terminar, sobre la parte baja y cenagosa del Almendares, vivían entonces la joven Rosa Alba de Luna, con su hermana mayor Georgina y su viejo padre Gustavo. Todos habían sido y eran burócratas, pero desde el cambio de régimen no trabajaba sino Georgina. Gustavo salía regularmente todos los días en busca de puesto. Con la misma regularidad volvía sin él, y era cada vez menos él mismo. (p. 77) ${ }^{17}$

16 Se refiere a Policarpo Soler, al que Thomas describe como "el más escandaloso, ultrajante y sangriento de los gangsters [sic] de los auténticos [el partido político de los presidentes Grau y Prío]" (THOMAS, 1974, p. 999). En su estudio sobre el bonchismo, Aguiar Rodríguez le dedica el apartado "Policarpo Soler y su pandilla" a las circunstancias que llevaron a Soler a exiliarse de Cuba en Madrid, Venezuela y República Dominica. En este último destino estuvo al servicio del dictador Leónidas Trujillo, por orden del cual fue finalmente asesinado.

17 Este asunto es recurrente en la prosa de ficción de Novás Calvo: En los traspatios (1946), "La luna nona" (publicado en La luna nona y otros cuentos, 1942), e incluso en El negrero (1933). En lo periodístico, destaca el reportaje titulado "Los vagabundos del mar" realizado en Espańa en 1936 para Mundo gráfico. Además, es difícil no entrever en la descripción del anciano cesado una proyección de la propia 
El patetismo con que se dibuja el deterioro anímico del viejo funcionario salpica esporádicamente el texto de amplias dosis de acerba crítica social, hasta alcanzar en los párrafos finales su dimensión máxima:

Su hermana sigue yendo, todos los días a la oficina, y su padre va y viene diariamente a la misma hora, como si también tuviera una misión regular que cumplir. Se le ve con frecuencia a la entrada y por los pasillos de los ministerios. Mira a los jefes y oficiales que entran y salen, los saluda y sonríe con tristeza. Pero ya no les pide nada. Ya no parece tener nada que pedirles. (p. 100)

Igualmente, diluido en el conjunto temático, sin recibir especial énfasis en el desarrollo de peripecias exigido por la trama, puede ser entrevisto otro rasgo descriptivo del contexto específico al que aluden las historias narradas: la salida forzada del país, tal y como puede comprobarse en " $¡ Y$ baila y baila y baila!", "Elsa Colina y los tantos millones" o "Historia de un asalto". Con éxito o sin él, en barca o en avión, los personajes ante el cariz de los acontecimientos acometen la riesgosa empresa del exilio, cuya realización adquiere matices equiparables a los esfuerzos desesperados de otros emigrantes protagonistas de los relatos de Novás Calvo. Aunque en esta ocasión no se desarrollen las penalidades sufridas durante el viaje y no intervengan en su planificación los contrabandistas humanos presentes en la ficción de "Long Island" - publicado en La luna nona y otros cuentos- o en la crónica aparecida en Bohemia en 1951 sobre el más famoso de ellos, Simonovitch el Zorro, la necesidad de fuga, la clandestinidad de los medios y la incertidumbre del destino emparientan entre sí estos textos, a través de uno de los asuntos más reiterados en su prosa:

Pasamos, en fila india, entre unos guardias. Uno de ellos paró al lanchero, pero no entendí lo que le dijo. El lanchero rió. Nosotros -yo y mi compañeroseguimos, uno tras otro, hacia la lancha. Habíamos entrado antes de que él llegara. El motor estaba andando. La lancha empezó luego a deslizarse muy suavemente a lo largo de la playa. Pasamos dulcemente ante las luces, que nos daban con intermitencia en la cara, lo mismo que los rumores de la gente. Yo sentía una indecible pesadez en todo el cuerpo. De aquellos últimos minutos, antes de virar hacia el norte y adentrarnos en el mar, tengo un vago recuerdo. Fue como un estado crepuscular entre el sueńo y la vigilia [...].

Se interrumpió [El lanchero] y, sacando un mapa, me indicó una islita en forma de cangrejo que, en el mapa, no parecía muy lejos, al nordeste de nuestra playa. (p. 125-126)

experiencia del autor, que al perder su puesto como profesor de francés en la Escuela Normal de Maestros de La Habana se vio sometido a circunstancias similares, que dejaron una huella de indeleble desencanto en su espíritu. 
Por último, como argumentan Fernández Pequeño (1995, p. 27) y Espinosa Domínguez (2004, p. 256), el lenguaje contribuye también a la cubanización de las ocho narraciones. De este modo, Novás Calvo consigue prolongar la línea marcada por la versión más realista del policial y mantener la coherencia con el resto de su literatura, donde la original recreación artística (no mimética) del habla habanera ha sido constantemente considerada como uno de los mayores aciertos y de las principales innovaciones de su prosa respecto a la narrativa anterior.

Se observa así la presencia de giros y léxico cubanos relacionados a menudo con la fauna, flora, comida, costumbres autóctonas: "un nido de guincho", "perfumada de ilang-ilang", "algo más en el ajiaco", "sale el gallo tapado" (se refiere a un número de la Charada, la lotería cubana, que equivale al número once o al noventa y nueve; en definitiva quiere expresar la revelación de algo sorprendente que se mantenía intencionalmente oculto), "la cosa anda enyerbada" ('enredada'), guizazo ('espina'), molote ('aglomeración de personas'), tonga ('pila ordenada de cosas'), guajiro, bohio, caraira ('ave de rapiña'), tranque ('embotellamiento'), trusa ('bañador'), encangrejarse ('no funcionar una máquina'), chichipó ('bebida gaseosa' y figurativamente 'lío'); o términos que adquieren en la isla un significado propio: máquina ('coche'), buscachivos ('prismáticos'), timón ('volante'), paraguayo ('machete'). Americanismos como prángana, parqueo, cabuya, guayabos o chalina. Préstamos lingüísticos en diferentes grados de asimilación: los galicismos ripostaron ('respondieron', propio de varios países caribeños), loge ('portería', 'piscina' o 'vestuario'), restorán, rouge ('pintalabios'); y abundantes anglicismos subrayados en cursiva como flash, training, show.

Destacan además algunos nombres de personajes que responden a esta técnica de concreción en la realidad caribeña: Jorungo (según el Nuevo catauro de cubanismos de Fernando Ortiz es usado en Cuba como 'persona mortificante, pesada' procede del uso en Venezuela de jorungar, que equivale a huronear en referencia a una persona que como un hurón "averigua y descubre los secretos"), Jigua (galicismo que alude a un "árbol corpulento"); o el americanismo Zocotrocos ('trozo grande'); e igualmente las denominaciones de las fincas de los doctores en las afueras de La Habana: "La Casimba" ('pozo natural de agua potable') y "El Conuco" ('porción de tierra para cultivar'). La jerga de los pistoleros en referencia a su organización y modos de actuación se plasma ocasionalmente en "La yegua ruina y el tiro chiquito" a través de términos que adquieren una peculiar significación en las palabras del hampón que funge como narrador: gatilleros ('gánsters'), pase o pasada ('ataque entre pandilleros con arma automática desde un coche'), conchunche ('conciliábulo'), cocinados ('detenidos e interrogados con dureza'). 
En conclusión, alacranados, acanallados, provenientes de distintos sectores de la sociedad, acosados por un poder corrompido y cruel o víctimas de su propia ignominia, a estos personajes les está vedada una respuesta ética o un comportamiento cívico aceptable. Infectados por el aguijón de la violencia, de la política o de la pasión malsana, quedan atrapados en una urdimbre de maldad que los obliga a tejer su propia red criminal para salvar la vida, satisfacer los deseos, reclamar venganza o demostrar su inculpabilidad. La insostenible situación social de La Habana de aquellos años se convierte en los cuentos criminales del autor en el agente externo que, sustituyendo a las revoluciones, mares, huracanes, manglares y cayos de su producción anterior, acosa al protagonista, le inyecta su ponzońa y a menudo lo arrastra hasta su inevitable aniquilación. La cubanización de estos relatos a través del escenario, los personajes y el lenguaje es un rasgo crucial de estas 8 narraciones policiales y convierte a Novás Calvo en punto de partida inexcusable del género policial contemporáneo en Cuba.

Referencias bibliográficas

AGUIAR RODRÍGUEZ, Raúl. El bonchismo y el gangsterismo en Cuba. La Habana: Ciencias Sociales, 2000.

ANDERSON-IMBERT, Enrique. La originalidad de Lino Novás Calvo Calvo. Symposium, v. 29, n. 3, 1975, p. 212-229.

ARENAS, Reinaldo. Antes que anochezca. Barcelona: Tusquets, 2010.

BATISTA FALLA,Víctor. ¿Adónde va nuestra narrativa? Exilio, otoño, 1972, p. 21-26.

BRAHAM, Persephone. Crimes against the State, crimes against persons. Detective fiction in Cuba and Mexico. Minneapolis and London: Minnesota UP, 2004.

CABRERA INFANTE, Guillermo. La luna nona de Lino Novás Calvo Calvo. En: Vidas para leerlas. Madrid: Alfaguara, 1998, p. 115-121.

ESPINOSA DOMÍNGUEZ, Carlos. Entre la provincia y el mundo: modernidad e innovación en la narrativa de Lino Novás Calvo. Tesis dirigida por Florence Yudin. Miami, Florida: Florida International University, 2004.

FERNÁNDEZ PEQUEÑO, José M. Lino Novás Calvo: del desarraigo a la paradoja. En: NOVÁS CALVO, Lino. 8 narraciones policiales. Santiago de Cuba: Oriente, 1995, p. 3-28.

GÓMEZ-DE-TEJADA, Jesús. Las posibilidades narrativas del crimen: raíces y huellas del género policial en Lino Novás Calvo. Bulletin of Hispanic Studies, vol. 90, n. 5, 2013a, p. 597-611. 
GÓMEZ-DE-TEJADA, Jesús. Lino Novás Calvo y la crónica roja: Crimen y periodismo en 8 narraciones policiales. En PARRA MEMBRIVES, Eva (ed.). Trivialidades literarias. Reflexiones en torno a la literatura de entretenimiento. Madrid: Visor, 2013b, p. 161-178.

GUEHERIN, David. Scene of the Crime. The Important of Place in Crime and Mistery Fiction. Jefferson, North Carolina; London: McFarland \& Company, Inc. Publishers, 2008.

GUTIÉRREZ DE LA SOLANA, Alberto. Novás Calvo: precursor y renovador. Symposium, vol. 29, n. 3, 1975, p. 243-254.

IRBY, James East. La influencia de William Faulkner en cuatro narradores hispanoamericanos. Tesis. México: Universidad Nacional Autónoma de México, 1956.

MARTÍN CEREZO, Iván. Poética del relato policiaco (de Edgar Allan Poe a Raymond Chandler). Murcia: Universidad de Murcia, Servicio de Publicaciones, 2006.

NOVÁS CALVO, Lino. La luna nona y otros cuentos. Buenos Aires: Nuevo Romance, 1942.

NOVÁS CALVO, Lino. Cayo Canas. Buenos Aires: Espasa-Calpe, 1946.

NOVÁS CALVO, Lino. Simonovitch y sus andanzas por tierras de Cuba. Bohemia, noviembre, 1951, p. 74-77; 80-81.

NOVÁS CALVO, Lino. Maneras de contar. New York: Las Américas, 1970.

NOVÁS CALVO, Lino. Crónica roja. Exilio, invierno, 1973, p. 95-102.

NOVÁS CALVO, Lino. 8 narraciones policiales. Fernández Pequeño, José M. (compilación y prólogo), Santiago de Cuba: Oriente, 1995.

NOVÁS CALVO, Lino. Laberinto de fuego. Epistolario de Lino Novás Calvo. Romero, Cira (recopilación y notas); Heras León, Eduardo (prólogo). La Habana: La Memoria, Centro Cultural Pablo de la Torriente Brau, 2008a.

NOVÁS CALVO, Lino. Novela por hacer. In: NOVÁS CALVO, Lino. Órbita de Lino Novás Calvo. César García, Julio (ed.); Romero, Cira (prólogo y selección). La Habana: Unión, 2008b, p. 392-405. [Aparecido por primera vez en Revista Bimestre Cubana, vol. XLVII, n. 3, mayo-junio, 1941, p. 348-359]

NOVÁS CALVO, Lino. Hammett y Cain. In: NOVÁS CALVO, Lino. Órbita de Lino Novás Calvo. La Habana: Unión, 2008c, p. 411-414.

NOVÁS CALVO, Lino. Un error de Alfonso Reyes. In: NOVÁS CALVO, Lino Órbita de Lino Novás Calvo. La Habana: Unión, 2008d, p. 427-430.

OAKLEY, Helen. From Revolution to Migration: a Study of Contemporary Cuban and Cuban-American Crime Fiction. Oxford; New York: Peter Lang, 2011.

PORTUONDO, José Antonio. Lino Novás Calvo Calvo y el cuento hispanoamericano. Cuadernos Americanos, septiembre-octubre, 1947, p. 245-263. 
PORTUONDO, José Antonio. Astrolabio. La Habana: Arte y Literatura, 1973.

ROMERO, Cira Fragmentos de interior. Lino Novás Calvo: su voz entre otras voces. Santiago de Cuba: Oriente, 2008.

THOMAS, Hugh. Cuba: la lucha por la libertad, 1762-1970. La República independiente, 1909-1958, vol. 2. Barcelona; México: Grijalbo, 1974. [Traducción de Cuba or the Pursuit of Freedom, London: Eyre \& Spottiswoode, 1971]

WILKINSON, Stephen. Detective Fiction in Cuban Society and Culture. Oxford: Peter Lang, 2006.

Jesús Gómez-de-Tejada. Professor e investigador na Universidad Autónoma de Chile. Coordena o projeto "Calibre corto: sendas del cuento policial cubano" (CONICYT, Chile). Autor de El negrero de Lino Novás Calvo y la biografía moderna (2013) e editor de Erotismo, transgresión y exilio: las voces de Cristina Peri Rossi (2017) e de Vidas extraordinarias. Crónicas biográficas y autobiográficas (1933-1936) (2014). Em colaboração com outros colegas editou Asedios al caimán letrado: literatura y poder en la Revolución cubana (2018). Tem publicado artigos, resenhas e entrevistas em periódicos acadêmicos, como Bulletin of Hispanic Studies, Revista Chilena de Literatura, Hispamérica ou Atenea, entre outros.

E-mail: manuel.gomezdetejada@uautonoma.cl 